\title{
An observational study of the association of vitamin $D$ status and other patient characteristics with COVID-19 severity and mortality
}

\author{
M. Connolly ${ }^{1,2}$, M. Youssef ${ }^{3}$, A. O'Shea ${ }^{1,2}$, A. Al Lawati' ${ }^{3}$ S.I. Shah ${ }^{3}$, S. Walsh ${ }^{3}$, D. McCartney ${ }^{1}$ \\ and J. Faul $\mathrm{F}^{3,4}$ \\ ${ }^{1}$ School of Biological and Health Sciences, Technological University Dublin, Ireland, \\ ${ }^{2}$ School of Medicine, Trinity College Dublin, Dublin, Ireland, \\ ${ }^{3}$ Department of Respiratory Medicine, Connolly Hospital Blanchardstown, Dublin, Ireland and \\ ${ }^{4}$ James Connolly Memorial Asthma Research Centre, Royal College of Surgeons in Ireland, Connolly Hospital \\ Blanchardstown, Dublin, Ireland
}

Vitamin D deficiency has been proposed to adversely affect COVID-19 severity and clinical outcome ${ }^{(1-4)}$. The current study aimed to evaluate the association between vitamin D status and COVID-19 severity and clinical outcome after adjustment for other factors thought to affect outcome including age and gender.

The study included 114 patients from Connolly Hospital, Blanchardstown, Dublin, all of whom tested positive for COVID-19 between March 2020 and May 2020. The independent variables examined included vitamin D status and age, gender, ethnicity, BMI, smoking status and number of comorbidities. Vitamin D status was classified as 'deficient' (serum $25(\mathrm{OH}) \mathrm{D}<30 \mathrm{nmol} / \mathrm{L})$, 'insufficient' (serum 25(OH)D of 30-49.9nmol/L) and 'sufficient' (serum $25(\mathrm{OH}) \mathrm{D} \geq 50 \mathrm{nmol} / \mathrm{L}$ ). The clinical outcomes assessed were ICU admission, oxygen requirement and mortality.

Out of the full cohort $(n=114), 64 \%$ were male and $17 \%$ were over the age of 70 . One fifth $(n=23)$ of the participants did not survive. The most common comorbidity was hypertension $(64 \%)$. When categorised according to vitamin $\mathrm{D}$ status ( $\mathrm{n}=94)$, 49 patients $(52 \%)$ were deficient, $20(21 \%)$ were insufficient and $25(27 \%)$ had sufficient serum $25(\mathrm{OH}) \mathrm{D}$ levels. Low vitamin D status was associated with greater mortality on univariate analysis, with $80 \%$ of those who died presenting with $25(\mathrm{OH}) \mathrm{D}$ levels $<30 \mathrm{nmol} / \mathrm{L}$ vs. $46 \%$ of those who survived $(\mathrm{P}=0.048)$. On multivariate regression analysis, the association between vitamin $\mathrm{D}$ deficiency $(25(\mathrm{OH}) \mathrm{D}<30 \mathrm{nmol} / \mathrm{l})$ and mortality was attenuated $(\mathrm{OR} 10.37,95 \% \mathrm{CI}=0.942-114.1, \mathrm{p}=0.056)$, but the association of vitamin $\mathrm{D}$ deficiency with increased requirement for oxygen therapy persisted $(\mathrm{OR}=3.75,95 \% \mathrm{CI}=1.01-13.9, \mathrm{P}=0.048)$. Males were more likely to require $\mathrm{ICU}$ admission $(\mathrm{OR}=3.43,95 \% \mathrm{CI}=1.01-11.65, \mathrm{P}=0.048)$ and oxygen therapy $(\mathrm{OR}=3.34,95 \% \mathrm{CI}=1.04-10.71$, $\mathrm{P}=0.042)$ than females. When adjusted for other confounders, patients over the age of 70 years were 21.5 times more likely to die than those under the age of 50 years $(\mathrm{OR}=21.5,95 \% \mathrm{CI}=2.25-205.4, \mathrm{P}=0.008)$.

In addition to older age ( $>70$ years) and male gender which both predict poorer clinical outcome, low vitamin D status appears to be an independent risk factor for more severe disease and mortality in COVID-19.

\section{References}

1. Pereira M, Dantas Damascena A, et al. (2020) Crit Rev Food Sci Nutr 1-9

2. Ali N (2020) J Infect Public Health 13(10), 1373-80

3. Faul JL, Kerley CP, Love B, et al. (2020) Ir Med J 113(5), 84

4. Ilie PC, Stefanescu S \& Smith L (2020) Aging Clin Exp Res 32(7), 1195-8 